\title{
Barriers and facilitators to diagnosing and managing apathy in Parkinson's disease: a qualitative study
}

\author{
Bria Mele ${ }^{1 *}$ D, Zahra Goodarzi ${ }^{2,3}$, Heather M. Hanson ${ }^{1,4}$ and Jayna Holroyd-Leduc 3,5
}

\begin{abstract}
Background: Apathy is a prominent non-motor symptom in Parkinson's disease (PD). People with apathy show a lack of emotion, passion, and motivation. Between 17 and 70\% of persons with PD have apathy; the extreme heterogeneity in these estimates is due to limited heterogeneous knowledge concerning how to diagnose PD. The lack of a widely utilized diagnostic process limits understandings on how to treat and manage apathy in PD. A scoping review of apathy in PD identified only one qualitative study investigating this symptom. It was our objective to assess perceived barriers and facilitators to diagnosing, treating, and managing apathy in PD, as described by key stakeholders.
\end{abstract}

Methods: This research applied qualitative methodology, utilizing focus groups and interviews with health care practitioners (HCPs), persons with PD, and caregivers. Evidence gathered from a scoping review on apathy in PD informed discussions that took place with participants. Data collection and analysis was conducted using framework analysis, applying the Theoretical Domains Framework and Behaviour Change Wheel.

Results: Eleven HCPs and five persons with PD/caregivers participated. Themes included interdisciplinary teams and communication with family to facilitate diagnosis and treatment, and the use of education and increased awareness of apathy to facilitate management. Themes surrounding barriers included lack of initiative and motivation to maintain treatment plans, and a lack of evidence for apathy specific interventions. While a key barrier identified was the lack of information HCPs have access to, persons with PD and caregivers would prefer to receive a diagnosis of apathy even with limited management methods. Thus, education and awareness were noted as two of the most important facilitators, overall.

Conclusion: These findings suggest that diagnosing, treating, and managing apathy in PD requires interdisciplinary teams, that include family and caregivers. We identified that where HCPs perceive lack of knowledge as a barrier to diagnosis, persons with PD and caregivers find being given a diagnosis facilitates understanding. These findings highlight the importance of qualitative research involving persons with PD and apathy, caregivers, and HCPs who aid in management of this symptom. Barriers reported suggest future research must aim to identify apathy specific treatments, both pharmacologic and non-pharmacologic.

Keywords: Parkinson's disease, Apathy, Diagnosis, Management, Qualitative research, Framework analysis

\footnotetext{
* Correspondence: bria.mele@ucalgary.ca

${ }^{1}$ Department of Community Health Sciences, University of Calgary, Foothills

Medical Centre, South Tower, Room 1104, 1403-29 St. NW, Calgary, AB T2N

2T9, Canada

Full list of author information is available at the end of the article
}

(c) The Author(s). 2019 Open Access This article is distributed under the terms of the Creative Commons Attribution 4.0 International License (http://creativecommons.org/licenses/by/4.0/), which permits unrestricted use, distribution, and reproduction in any medium, provided you give appropriate credit to the original author(s) and the source, provide a link to the Creative Commons license, and indicate if changes were made. The Creative Commons Public Domain Dedication waiver (http://creativecommons.org/publicdomain/zero/1.0/) applies to the data made available in this article, unless otherwise stated. 


\section{Background}

Apathy is present in $17-70 \%$ of persons with Parkinson's disease (PD) $[1,2]$. It is primarily conceptualized as a dysfunction in motivated behavior, causing individuals to feel a lack of emotion, passion, and motivation [3, 4]. Apathy has also been conceptualized as a disorder of self-initiative and motivation affecting emotion, cognition, and overt behaviour [4]. Apathy contributes significantly to poor quality of life in those with $\mathrm{PD}$, compared to other non-motor symptoms $[5,6]$.

Despite how common apathy is, there are no universally accepted diagnostic criteria, however several diagnostic criteria have been proposed [7, 8]. While such diagnostic criteria have been validated within PD populations, recent updates have been published and require further validation $[7,9]$. Furthermore, the lack of universally accepted diagnostic criteria results in variation in how screening tools to detect apathy in PD are validated. The variation in assessment of psychometric properties results in heterogeneous understandings of apathy within the literature [2]. This subsequently limits the information and support given to persons with PD and their family caregivers [10]. As family caregivers often provide care for individuals with $\mathrm{PD}$, this symptom affects more than those with PD and is an important focus for research $[11,12]$.

The lack of widely utilized diagnostic criteria for apathy in PD is a key problem surrounding the diagnosis and treatment of this symptom $[13,14]$. PD specific apathy rating scales have been developed and validated within PD populations [13-15]. However, these scales have not been validated using an accepted definition for apathy $[14,16]$. Given the heterogeneity associated with the validation of available apathy screening tools, they have not been consistently adopted across the literature $[2,15]$. Research highlights the importance of validating such tools against an accepted gold standard criteria for apathy [15]. Thus, the current lack of consensus regarding a definition and approach to diagnosis remains an important gap within the literature.

Treatment options for apathy in PD are also lacking $[17,18]$. In a preceding scoping review, our team synthesized all available literature on diagnosing and managing apathy in PD [19]. This synthesis provided an understanding of what is currently known, and where gaps exist. Of the 323 included studies on apathy and PD, there were no conclusive findings regarding effective treatment for apathy in PD, either pharmacological or non-pharmacological [20].

As gaps within the literature have been clearly identified, research must assess why these gaps exist and determine the facilitators and barriers to care. This will ensure meaningful future steps are taken to improve the quality of care provided to those with PD and apathy.
Therefore, our primary objective was to assess patient, family caregiver, and health care practitioners (HCP) perceptions around the barriers and facilitators to diagnosing and managing apathy in PD.

\section{Methods \\ Design and ethics}

This study employed semi-structured focus groups and interviews and used framework analysis to analyze data. Both focus groups and interviews were employed to ensure flexibility with participant schedules. Ethics approval was granted through the Conjoint Health Research Ethics Board (CHREB-17-0669). All researchers involved and participants signed confidentiality agreements and informed consent.

\section{Context, setting, and sampling}

The use of theoretical thematic analysis, applying the Theoretical Domains Framework (TDF) and Behaviour Change Wheel (BCW), ensured evidence and interventions were directly linked. We estimated between four to six individuals per stakeholder group would be required to reach saturation [21].

Participants were divided into two groups: i) HCP including physicians, nurses, and allied health professionals and ii) persons with PD and apathy and/or their family caregivers. This was done to understand how different stakeholder groups use knowledge, and to help ensure persons with PD and their family caregivers would feel comfortable sharing their opinions. All participants spoke English, were not aphasic, and were able to provide informed consent.

HCP were recruited via convenience sampling. Practitioners were included if they were a neurologist, psychiatrist, psychologists, nurse, or allied health professional within the Calgary Movement Disorder Clinic (MDC), and had experience managing apathy in at least one individual with PD. HCP were contacted via email.

Patients were recruited via a convenience sample from within the MDC. Patients were included if they had a diagnosis of idiopathic PD made by a movement disorder specialist and a Starkstein Apathy Scale (SAS) score of 14 or greater. The SAS has a sensitivity of $66 \%$ and specificity of $100 \%$ [22, 23]. Individuals were excluded if they had significant symptoms of depression based on a score of 9 or above on the short form of the Geriatric Depression Scale [24, 25] or evidence of significant cognitive impairment based on a score of 4 or less on the Memory Impairment Screen [26]. These assessments were administered via telephone, prior to recruitment. Family caregivers of included individuals were also invited to participate. 


\section{Data collection and handling}

Interview guides were developed with the aim of understanding what stakeholders perceive to be the barriers and facilitators to an optimal approach to diagnosing and managing apathy in PD. Interview guides were informed by the TDF, and a preceding scoping review of apathy diagnosis and management in PD. All guides were reviewed by members of the research team and granted approval for use by the CHREB.

One facilitator conducted focus groups (B.M.), with a note-taker (J.H-L. or Z.G.). One researcher facilitated interviews (B.M.). The researcher who facilitated focus groups and interviews (B.M.) recorded their own answers to the interview guide, to bracket researcher bias prior to beginning facilitation [27]. Focus groups and interviews were recorded using an audio recorder and transcribed verbatim, using notes taken during focus groups to assess reflexivity [27]. Upon completion of focus groups, debriefing discussions took place between the facilitator and note-taker and were documented. All transcripts had identifying factors removed and $10 \%$ of transcripts were checked for consistency with audio recordings. Data were analyzed using NVivo (11.4.0).

\section{Analysis}

Framework analysis was utilized to analyze transcripts. This analytic technique requires data to be summarized and classified into a thematic framework [21]. The thematic framework was based on the TDF and $\mathrm{BCW}$, producing findings focused on practice-oriented results [21]. The TDF identifies 14 theoretical domains associated with the psychology of behavior change [28]. The $\mathrm{BCW}$ is concerned with how to successfully implement interventions by matching change interventions to behavioural barriers; an individual's capability, opportunity, and motivation interrelate and influence their behaviour (COM-B) [29].

The primary researcher (B.M.) developed initial codes and themes for all transcripts. The first $25 \%$ of coding was reviewed iteratively with two members of the research team (Z.G. and H.H.). After this point, all coding was verified by Z.G. Three researchers (B.M., Z.G., and H.H.) assigned codes and themes to the TDF and BCW categories. These themes were then reviewed again by all four researchers (H.H., Z.G., J.H-L., and B.M.) to confirm all final coding and theme assignment.

\section{Results \\ Participants (Tables 1 and 2 to be placed below this paragraph)}

A total of two focus groups and eight interviews took place, including a total of 16 participants ( 11 females). If participants were unable to attend focus groups, interviews took place (Tables 1 and 2). HCP had experience ranging from $<1$ year to 20 years. The percentage of persons with PD and apathy that the HCP had seen during their practice ranged from 5 to $70 \%$. All persons with PD were recruited from the Calgary MDC. Ages ranged from 59 to 72 years, with PD duration ranging from 3 to 15 years. Duration of apathy ranged from 2 to 10 years.

\section{Barriers and facilitators to diagnosis (Table 3 to be placed below this paragraph)}

Words in parentheses below represent the TDF domain(s) associated with the given code.

Apart from initial screening for inclusion within this study, patients included within this study stated they had never received a formal diagnosis of apathy (Knowledge, Skills) (Table 3). HCP reported they may be aware of apathy without making a formal diagnosis (Knowledge, Skills). It was identified that apathy is difficult to see and may present in a variety of ways (Optimism, Knowledge). While some HCP reported a screening tool may be helpful when ruling out comorbidities that present with apathy (Knowledge, Skills, Memory, attention and decision processes), overall it was reported there is limited use to screening tools for apathy if there is no formally accepted definition of apathy (Knowledge, Beliefs about capabilities).

"I personally was never diagnosed with apathy, I just know I have it." PTC P1

"I've never been diagnosed with apathy either ... There's no formal diagnosis ever been offered of apathy" PTC P3

"There's no definition or diagnostic criteria for apathy, that makes it virtually impossible to categorize. The

Table 1 Description of Persons with PD and Caregivers Included

\begin{tabular}{|c|c|c|c|c|c|}
\hline Focus Group or Interview & Person with $\mathrm{PD}$, or caregiver, or $\mathrm{HCP}$ & Gender & Age & Duration of Parkinson's Disease (years) & Duration of apathy (years) \\
\hline Focus Group \#1 & Person with PD & M & $61-65$ & $1-5$ & 2 \\
\hline Focus Group \#1 & Person with PD & $\mathrm{F}$ & $56-60$ & $11-15$ & 10 \\
\hline Focus Group \#1 & Caregiver & M & $61-65$ & NA & NA \\
\hline Interview & Person with PD & $\mathrm{F}$ & $71-75$ & $6-10$ & 2 \\
\hline Interview & Person with PD & $\mathrm{F}$ & $66-70$ & $1-5$ & 4 \\
\hline
\end{tabular}


Table 2 Description of HCPs Included

\begin{tabular}{llll}
\hline Interview & F & 2 & 10 \\
\hline Interview & F & 9 & 70 \\
Interview & $M$ & $<1$ & 5 \\
Interview & $M$ & 18 & 50 \\
Interview & $M$ & 8 & 60 \\
Focus Group \#2 & F & 20 & NR \\
Focus Group \#2 & F & 32 & 10 \\
Focus Group \#2 & F & 20 & 15 \\
Focus Group \#2 & F & 15 & $20-30$ \\
Focus Group \#2 & F & NR & NR \\
Interview & F & NR & 50 \\
\hline
\end{tabular}

scoping systems [reviews] can say well, you know, you scored kind of in the I got apathy zone ... but there's no real way to diagnose it" PTC P3

A key barrier to diagnosis identified was the lack of awareness of neuropsychiatric symptoms in PD, including apathy (Knowledge, Beliefs about capabilities, Social/ professional role and identity). HCP identified the overall lack of engagement and insight among those with PD and apathy is an additional barrier to diagnosis (Beliefs about capabilities, Emotion). It was also reported that apathy may go purposefully unreported in care facilities because passive behaviour is favorable (Intentions, Beliefs about consequences).

"So, I think the lack of awareness is a big problem, not only for apathy, for all the non-motor symptoms of the disease." HCP P2

“... this state I'm in, I don't think I was mentally prepared for this so like you say that might be a good, like had I known then it's just like ok this is a possibility this may happen or along that line ..." Patient/Caregiver (PTC) P1

“ ... people with apathy often come, with more severe apathy obviously, they come through as being ... quite disengaged in the way they give an account of their day and ... the type of emotional accompaniment to their speech is a red flag ... they are not very collaborative ..." HCP P4

" ... they live in a care facility, and I think care facilities probably don't mind apathy as much as other things and so the impetus then to report is quite a bit lower." HCP P5

All included participants agreed there needs to be increased awareness of apathy as a symptom in PD
(Knowledge, Goals). Increased education on apathy as a symptom in PD was thought to aid HCP in making a diagnosis (Knowledge, Skills). With some participants suggesting research applying focus groups and qualitative methods may aid in increasing awareness of apathy (Beliefs about consequences, Social influences). It was also reported that a variety of HCP should be able to identify apathy to facilitate diagnosis (Beliefs about capabilities, Social/professional role and identity).

“... even if you can't do anything about it, to create an understanding of it for patients and families ... I've under appreciated the value of that, I think ... and I probably still do. I think for families to say ... we know what this is, it has a name, is really empowering for them." HCP P5

"I think education about identifying, specifically targeting ... being more aware of behaviours that might indicate apathy, having it more on the radar, maybe. I think depression tends to be up there but apathy it seems to be a little bit of a harder [symptom]." HCP P6

“... it's one [the diagnosis of apathy] that really should cut across a number of different specialties that work within the clinic and ... I think the typical practitioner that makes it [the diagnosis of apathy] is probably the psychiatrist, or neuropsychiatrist that works in a clinic." HCP P5

Facilitators to diagnosis included communication between HCP and family/persons with PD (Memory, attention and decision processes, Behavioural regulation, Social/ professional role and identity, Reinforcement, Skills). Other facilitators to diagnosis were, knowing that apathy can exist as a symptom isolated from other neuropsychiatric symptoms or as a symptom along with other neuropsychiatric symptoms (Knowledge, Memory, attention and decision processes, Intentions, Beliefs about consequences).

"I don't use it [screening tools] in the practice, I usually go based mostly on the family history ... and I talk to the patient about this also because usually when they tell me about it, they can recognize some aspects [of apathy].” HCP P2

"Those who have apathy also have quite significant depression or cognitive impairment." HCP P1

"I try and dispel misconceptions about it, particularly one of the more common misconceptions is that their relative is in fact depressed, and suffering from a sadness or a dislike of whatever the activities are." HCP P5 
Table 3 Barriers and Facilitators to the diagnosis of apathy in PD using the COM-B and TDF framework

\begin{tabular}{|c|c|c|c|c|}
\hline \multicolumn{2}{|c|}{ COM-B System } & TDF & \multirow{2}{*}{$\begin{array}{l}\text { Diagnosis Related Codes } \\
\text { A variety of screening tools are used to identify neuropsychiatric } \\
\text { symptoms other than apathy }\end{array}$} & \multirow{2}{*}{$\begin{array}{l}\text { Facilitator or } \\
\text { Barrier } \\
\text { Facilitator }\end{array}$} \\
\hline Capability & Psychological & & & \\
\hline & & & Apathy as dynamic changing symptom & Barrier \\
\hline & & & $\begin{array}{l}\text { Apathy exists as a symptom isolated from other neuropsychiatric } \\
\text { symptoms }\end{array}$ & Facilitator \\
\hline & & & Apathy is often diagnosed with other neuropsychiatric symptoms & Facilitator \\
\hline & & & Apathy presents in a variety of ways & Barrier \\
\hline & & & $\begin{array}{l}\text { Education on apathy as a symptom in PD aids health care practitioners } \\
\text { in making a diagnosis }\end{array}$ & Facilitator \\
\hline & & & Recognizable symptoms in those with apathy in PD & Facilitator \\
\hline & & & Knowing about apathy facilitates diagnosis & Facilitator \\
\hline & & & $\begin{array}{l}\text { Lack of awareness of apathy as a symptom hinders diagnostic and } \\
\text { management processes }\end{array}$ & Facilitator \\
\hline & & & Lack of screening tools for apathy & Barrier \\
\hline & & & $\begin{array}{l}\text { Health care practitioner may be aware of apathy without making a } \\
\text { formal diagnosis }\end{array}$ & Barrier \\
\hline & & & Limited utility of screening tools if there is not one definition for apathy & Barrier \\
\hline & & & $\begin{array}{l}\text { Need to create increased awareness that apathy is a part of the } \\
\text { non-motor symptoms in PD }\end{array}$ & Barrier \\
\hline & & & Physicians require diagnostic process prior to providing management & Barrier \\
\hline & & Skills & $\begin{array}{l}\text { A variety of screening tools are used to identify neuropsychiatric } \\
\text { symptoms other than apathy }\end{array}$ & Facilitator \\
\hline & & & $\begin{array}{l}\text { Education on apathy as a symptom in PD aids health care practitioners } \\
\text { in making a diagnosis }\end{array}$ & Facilitator \\
\hline & & & Getting patient history helps health care practitioner make diagnosis & Facilitator \\
\hline & & & $\begin{array}{l}\text { Health care practitioners use varied diagnostic processes to identify } \\
\text { apathy in PD }\end{array}$ & Barrier \\
\hline & & & Recognizable symptoms in those with apathy in PD & Facilitator \\
\hline & & & Knowing about apathy facilitates diagnosis & Facilitator \\
\hline & & & $\begin{array}{l}\text { Health care practitioner may be aware of apathy without making a } \\
\text { formal diagnosis }\end{array}$ & Barrier \\
\hline & & $\begin{array}{l}\text { Memory, attention and } \\
\text { decision processes }\end{array}$ & $\begin{array}{l}\text { A variety of screening tools are used to identify neuropsychiatric } \\
\text { symptoms other than apathy }\end{array}$ & Facilitator \\
\hline & & & $\begin{array}{l}\text { Apathy exists as a symptom isolated from other neuropsychiatric } \\
\text { symptoms }\end{array}$ & Facilitator \\
\hline & & & Apathy is often diagnosed with other neuropsychiatric symptoms & Facilitator \\
\hline & & & $\begin{array}{l}\text { Family and persons with PD communicating symptoms and behaviour } \\
\text { changes to physician aids diagnostic process }\end{array}$ & Facilitator \\
\hline & & & Getting patient history helps health care practitioner make diagnosis & Facilitator \\
\hline & & & $\begin{array}{l}\text { Health care practitioners use varied diagnostic processes to identify } \\
\text { apathy in PD }\end{array}$ & Barrier \\
\hline & & & Recognizable symptoms in those with apathy in PD & Facilitator \\
\hline & & Behavioural Regulation & $\begin{array}{l}\text { Family and persons with PD communicating symptoms and behaviour } \\
\text { changes to physician aids diagnostic process }\end{array}$ & Facilitator \\
\hline \multirow[t]{2}{*}{ Opportunity } & \multirow[t]{2}{*}{ Physical } & \multirow{2}{*}{$\begin{array}{l}\text { Environmental Context and } \\
\text { Resources }\end{array}$} & Screening tools to overcome lack of knowledge or experience & Facilitator \\
\hline & & & Lack of screening tools for apathy & Barrier \\
\hline \multirow[t]{2}{*}{ Motivation } & \multirow[t]{2}{*}{ Reflective } & \multirow[t]{2}{*}{ Beliefs about capabilities } & $\begin{array}{l}\text { A range of health care practitioners should be able to identify apathy } \\
\text { to aid diagnosis }\end{array}$ & Facilitators \\
\hline & & & Physicians require diagnostic process prior to providing management & Barrier \\
\hline
\end{tabular}


Table 3 Barriers and Facilitators to the diagnosis of apathy in PD using the COM-B and TDF framework (Continued)

\begin{tabular}{|c|c|c|c|}
\hline COM-B System & TDF & Diagnosis Related Codes & $\begin{array}{l}\text { Facilitator or } \\
\text { Barrier }\end{array}$ \\
\hline & \multirow{7}{*}{$\begin{array}{l}\text { Social/professional role } \\
\text { and identity }\end{array}$} & Screening tools may interfere with physician expertise and judgment & Barrier \\
\hline & & Screening tools to overcome lack of knowledge or experience & Facilitator \\
\hline & & $\begin{array}{l}\text { Inherent lack of engagement in those with apathy makes diagnosis } \\
\text { difficult }\end{array}$ & Barrier \\
\hline & & $\begin{array}{l}\text { Lack of awareness of apathy as a symptom hinders diagnostic and } \\
\text { management processes }\end{array}$ & Barrier \\
\hline & & Limited utility of screening tools if there is not one definition for apathy & Barrier \\
\hline & & $\begin{array}{l}\text { A range of health care practitioners should be able to identify apathy to } \\
\text { aid diagnosis }\end{array}$ & Facilitator \\
\hline & & $\begin{array}{l}\text { Lack of awareness of apathy as a symptom hinders diagnostic } \\
\text { and management processes }\end{array}$ & Barrier \\
\hline & Intentions & Apathy in care facility may purposefully go underreported & Barrier \\
\hline & \multirow{2}{*}{$\begin{array}{l}\text { Beliefs about } \\
\text { consequences }\end{array}$} & Apathy in care facility may purposefully go underreported & Barrier \\
\hline & & Need for a diagnostic tool for apathy & Barrier \\
\hline & Optimism & Apathy symptoms are difficult to see & Barrier \\
\hline & \multirow[t]{2}{*}{ Goals } & Need for a diagnostic tool for apathy & Barrier \\
\hline & & $\begin{array}{l}\text { Need to create increased awareness that apathy is a part of the } \\
\text { non-motor symptoms in PD }\end{array}$ & Barrier \\
\hline \multirow[t]{4}{*}{ Automatic } & \multirow{2}{*}{$\begin{array}{l}\text { Social/Professional Role } \\
\text { and Identity }\end{array}$} & Screening tools may interfere with physician expertise and judgment & Barrier \\
\hline & & $\begin{array}{l}\text { Family and persons with PD communicating symptoms and } \\
\text { behaviour changes to physician aids diagnostic process }\end{array}$ & Facilitator \\
\hline & Reinforcement & $\begin{array}{l}\text { Family and persons with PD communicating symptoms and behaviour } \\
\text { changes to physician aids diagnostic process }\end{array}$ & Facilitator \\
\hline & Emotion & $\begin{array}{l}\text { Inherent lack of engagement in those with apathy makes } \\
\text { diagnosis difficult }\end{array}$ & Barrier \\
\hline
\end{tabular}

"I started to notice that for depression I ... feel that ... you feel down, you feel teary. But apathy is totally different, apathy just is, you just don't really want to get involved and really there's nothing in my life that's horrible so I couldn't really understand why I felt so ... you know disengaged, definitely disengaged.” PTC P5

\section{Barriers and facilitators to overall management (Table 4 to be placed below this paragraph)}

Physicians reported they manage apathy based on experience versus evidence, as there are currently no guidelines for care of apathy in PD (Skills, Environmental context and resources) (Table 4). Furthermore, it was reported there is a lack of resources available pertaining to apathy treatment in PD (Knowledge, Environmental context and resources). A lack of evidence concerning apathy was part of a larger issue identified; overall there is limited information on neuropsychiatric symptoms of PD (Knowledge). This limits the capacity for HCP to provide treatment options to persons with PD (Beliefs about capabilities, Environmental context and resources).
"Again, there are not many guidelines, I really like evidence based medicine and there are not good guidelines for this [apathy]. The evidence is very poor." HCP P2

“... there's a remarkable amount of literature that sort of describes like the 10 cardinal symptoms of PD and you know, this is what PD is and this is what PD patients do. There's a significant ... lack of attention to this whole complex of motivation, apathy, joy, reward ... if they [newly diagnosed person with PD] haven't been told that this [apathy] could be a significant problem, they're certainly lead astray ..." PTC P3

[On the biggest barrier to managing apathy in PD] “ ... probably not enough facilities, or not enough capacity for all allied health professionals to take on this problem" HCP P4

"We need a pathway of care that is focused on apathy, we need an algorithm of treatment that makes the approach more standardized and helps interaction with other health professionals." HCP P4 
Table 4 Barriers and Facilitators to the management of apathy in PD using the COM-B and TDF framework.

\begin{tabular}{|c|c|c|c|c|}
\hline \multicolumn{2}{|c|}{ COM-B System } & TDF & Management Related Codes & $\begin{array}{c}\text { Facilitator o } \\
\text { Barrier }\end{array}$ \\
\hline \multirow{22}{*}{ Capability } & \multirow{22}{*}{ Psychological } & \multirow{12}{*}{ Knowledge } & Apathy gets worse as PD progresses & Facilitator \\
\hline & & & Awareness of apathy outside of the context of PD & Facilitator \\
\hline & & & Gaining knowledge on apathy in PD via experts in the field and their publications & \begin{tabular}{|l} 
Facilitator \\
Bartier
\end{tabular} \\
\hline & & & Limited information on neuropsychiatric symptoms of PD & Barrier \\
\hline & & & Apathy may improve with treatment of the motor-symptoms & Facilitator \\
\hline & & & There is a relationship between apathy and DBS & Facilitator \\
\hline & & & Dopamine as key neurotransmitter involved in mechanisms of apathy & Facilitator \\
\hline & & & Lack of sufficient evidence for how to treat apathy in PD & Barrier \\
\hline & & & $\begin{array}{l}\text { Health care practitioners are overall inexperienced with non-pharmacologic treatment } \\
\text { options }\end{array}$ & Barrier \\
\hline & & & Non-pharmacological treatment option examples & Facilitator \\
\hline & & & Pharmacologicaloptions for treatment & Facilitator \\
\hline & & & Treatment of other neuropsychiatric symptoms that present with apathy aids management & Facilitator \\
\hline & & \multirow{4}{*}{ Skills } & Awareness of apathy outside of the context of PD & Facilitator \\
\hline & & & $\begin{array}{l}\text { Physicians manage apathy based on experience versus evidence (i.e. apathy specific } \\
\text { guidelines) }\end{array}$ & Barrier \\
\hline & & & $\begin{array}{l}\text { Health care practitioners are overall inexperienced with non-pharmacologic treatment } \\
\text { options }\end{array}$ & Barrier \\
\hline & & & Treatment of other neuropsychiatric symptoms that present with apathy aids management & \begin{tabular}{|l|l|l|l} 
Facilitator \\
\end{tabular} \\
\hline & & \multirow{5}{*}{$\begin{array}{l}\text { Memory, attention } \\
\text { and decision } \\
\text { processes }\end{array}$} & Apathy is a prodromal feature of cognitive decline & Facilitator \\
\hline & & & $\begin{array}{l}\text { Health care practitioners use complex decision making and problem solving process to } \\
\text { manage apathy in PD }\end{array}$ & Barrier \\
\hline & & & $\begin{array}{l}\text { Management is made difficult when apathy presents with other neuropsychiatric } \\
\text { symmtoms }\end{array}$ & Barrier \\
\hline & & & Pharmacological options for treatment & Facilitator \\
\hline & & & Treatment of other neuropsychiatric symptoms that present with apathy aids management & Facilitator \\
\hline & & \begin{tabular}{|l} 
Behavioural \\
Regulation \\
\end{tabular} & Patient and caregiver to adjust daily activity expectations as method of management & Facilitator \\
\hline \multirow{17}{*}{ Opportunity } & \multirow{7}{*}{ Social } & \multirow[t]{7}{*}{ Social Influences } & Caregivers play a key role when it comes to patient management and outcomes & Facilitator \\
\hline & & & $\begin{array}{l}\text { Gaining knowledge on apathy in PD via experts in the field and their publications } \\
\text { Gender (family) roles interrupted by apathy }\end{array}$ & \begin{tabular}{|l|l|l|l} 
Facilitator \\
Barrier
\end{tabular} \\
\hline & & & $\begin{array}{l}\text { Health care practitioners use complex decision making and problem solving process to } \\
\text { manage apathy in PD }\end{array}$ & Barrier \\
\hline & & & $\begin{array}{l}\text { Interdisciplinary care team helps address management needs } \\
\text { Lack of social circle or family as limitation to care }\end{array}$ & \begin{tabular}{|l|l|l} 
Facilitator \\
Barrier
\end{tabular} \\
\hline & & & Patients perceive apathy to be part of natural aging process & Barrier \\
\hline & & & $\begin{array}{l}\text { Research applying focus groups and qualitative methods may aid in increasing awareness } \\
\text { of apathy as a symptom }\end{array}$ & Facilitator \\
\hline & & & $\begin{array}{l}\text { Key non-pharmacologic treatments include patient and family awareness, education, and } \\
\text { scheduled activities }\end{array}$ & Facilitator \\
\hline & \multirow{10}{*}{ Physical } & $\begin{array}{l}\text { Environmental } \\
\text { Context and }\end{array}$ & $\begin{array}{l}\text { Physicians manage apathy based on evidence versus evidence (i.e. apathy specific } \\
\text { guidelines) }\end{array}$ & Barrier \\
\hline & & & $\begin{array}{l}\text { Health care practitioners use complex decision making and problem solving process to } \\
\text { manage apathy in PD }\end{array}$ & Barrier \\
\hline & & & Interdisciplinary care team helps address management needs & Facilitator \\
\hline & & & $\begin{array}{l}\text { Lack resources available on apathy in PD } \\
\text { Limited access to interdisciplinary team }\end{array}$ & \begin{tabular}{|l|l} 
Barrier \\
Barrier
\end{tabular} \\
\hline & & & $\begin{array}{l}\text { Limited access to interdisciplinary team } \\
\text { Rey non-pharmacologic treatments include patient and family awareness, education, and } \\
\text { scheduled activities }\end{array}$ & \begin{tabular}{|l|l|l|l} 
Barner \\
Facilitator \\
\end{tabular} \\
\hline & & & Lack of sufficient evidence for how to treat apathy in PD & \begin{tabular}{|l|l|l|l} 
Bartier \\
\end{tabular} \\
\hline & & & $\begin{array}{l}\text { Lack of management methods may make health care practitioners feel making a diagnosis } \\
\text { is futile }\end{array}$ & Barrier \\
\hline & & & Limited capacity for health care practitioners to provide treatment for apathy in $\mathrm{PD}$ & \begin{tabular}{|ll} 
Barrier \\
\end{tabular} \\
\hline & & & Limited non-pharmacologic resources provided & \begin{tabular}{|l|l} 
Bartier \\
\end{tabular} \\
\hline & & & Non-pharmacological treatment option examples & \begin{tabular}{|l|l|l|l} 
Facilitator \\
\end{tabular} \\
\hline COM-B Syst & & & Diagnosis Related Codes & $\begin{array}{l}\text { Facilitator or } \\
\text { Barrier }\end{array}$ \\
\hline & & & Pharmacological options for treatment & Facilitator \\
\hline Motivation & Reflective & Beliefs about & Awareness of apathy outside of the context of PD & Facilitator \\
\hline & & capabilities & Caregivers play a key role when it comes to patient management and outcomes & Facilitator \\
\hline & & & Health care practitioners have limited exposure to apathy in PD & \begin{tabular}{|l|l|} 
Barrier \\
\end{tabular} \\
\hline & & & Lack of social circle or family as limitation to care & Barrier \\
\hline & & & Inherent lack of engagement in those with apathy makes treatment difficult & Barrier \\
\hline & & & Lack of hope surrounding effectiveness of treatment methods & Barrier \\
\hline & & & $\begin{array}{l}\text { Lack of management methods may make health care practitioners feel making a } \\
\text { diagnosis is futile }\end{array}$ & Barrier \\
\hline & & & Limited capacity for health care practitioners to provide treatment for apathy in PD & Barrier \\
\hline & & Social/professional & Caregivers play a key role when it comes to patient management and outcomes & Facilitator \\
\hline & & role and identity & Interdisciplinary care team helps address management needs & Facilitator \\
\hline & & & Patient and caregiver to adjust daily activity expectations as method of management & Facilitator \\
\hline & & & Patients perceive apathy to be part of natural aging process & Barrier \\
\hline & & & $\begin{array}{l}\text { Key non-pharmacologic treatments include patient and family awareness, } \\
\text { education, and scheduled activities }\end{array}$ & Facilitator \\
\hline & & Intentions & Patients use structured activities and planning as a form of management & Facilitator \\
\hline & & & $\begin{array}{l}\text { Lack of management methods may make health care practitioners feel making a } \\
\text { diagnosis is futile }\end{array}$ & Barrier \\
\hline & & $\begin{array}{l}\text { Beliefs about } \\
\text { consequences }\end{array}$ & Patients perceive apathy to be part of natural aging process & Barrier \\
\hline & & & $\begin{array}{l}\text { Research applying focus groups and qualitative methods may aid in increasing } \\
\text { awareness of apathy as a symptom }\end{array}$ & Facilitator \\
\hline & & & Lack of hope surrounding effectiveness of treatment methods & Barrier \\
\hline & & Optimism & Lack of hope surrounding effectiveness of treatment methods & Barrier \\
\hline & & Goals & Patients use structured activities and planning as a form of management & Facilitator \\
\hline & & & Inherent lack of engagement in those with apathy makes treatment difficult & Barrier \\
\hline & Automatic & Social Professional & Apathy causes change in patient personhood & Barrier \\
\hline & & Role and Identity & Gender (family) roles interrupted by apathy & Barrier \\
\hline & & Reinforcement & Caregivers play a key role when it comes to patient management and outcomes & Facilitator \\
\hline & & Emotion & Apathy causes change in patient personhood & Barrier \\
\hline & & & Apathy is a part of the disease, not the person & \begin{tabular}{|l} 
Facilitator \\
\end{tabular} \\
\hline & & & Burden of apathy & Barrier \\
\hline & & & Inherent lack of engagement in those with apathy makes treatment difficult & Barrier \\
\hline
\end{tabular}


Pharmacologic options for treatment are often considered a first line intervention or a quick fix, with most information coming from control trials (Knowledge, Memory, attention, and decision processes, Environmental context and resources). Often, it was reported that the treatment of other neuropsychiatric symptoms that present with apathy aids management (Knowledge, Skill, Memory, attention and decision processes).

“... one quick way to try and improve it [apathy] would be pharmacological. So, and I gauge their acceptance of adding on a medication of that type." HCP P4

"I am not aware of any treatments that specifically target apathy outside of the context of where it occurs with other diagnoses. So, I have seen apathy improve in patients with cognitive impairment who go on ... cholinesterase inhibitors. And in patients with depression I have seen apathy improve with antidepressants but also with stimulant medications." HCP P1

However, persons with PD prefer non-pharmacologic interventions and feel there are limited non-pharmacologic resources provided (Environmental context and resources). HCP reported that overall, they are inexperienced with non-pharmacologic treatment (Knowledge, Skill).

"... whereas personally the less medication you're on the better I think but if there are tools you know for example ... you mention exercise in your ... nonprescription medication [s] [to] treat apathy aren't extensive but would be worthwhile I think." PTC P3

HCP reported the lack of evidence for management contributed to feeling a sense of futility in making the diagnosis (Beliefs about capabilities, Environmental context and resources, Intentions). HCP also described a lack of hope surrounding the effectiveness of treatment methods for apathy in PD (Beliefs about capabilities, Beliefs about consequences, Optimism). However, persons with PD and their caregivers preferred to receive a diagnosis of apathy, with awareness and education on apathy reported as key techniques for management (Knowledge, Social/professional role and identity, Environmental context and resources, Social influences).

"I also think the treatment refractory nature of it [apathy] ... pharmacologically, I think a lot of physicians have the mindset, if you can't fix it with a drug then I don't know why they're seeing me for it." HCP P5

"I don't have a strong level of hope that any treatment is really going to make a big difference for people." HCP P1
"I find that some of the neurologists are a little bit hesitant to discuss kind of mental components of PD, apathy being one of them, motivation etc." PTC P3

All participants reported family caregivers play a key role when it comes to patient management and outcomes (Social/professional role and identity, Beliefs about capabilities, Social influences, Reinforcement). It was also identified that interdisciplinary care teams can address management needs (Social/Professional Role and Identity, Environmental Context and Resources, Social Influences). However, our findings suggest there is limited access to interdisciplinary teams (Environmental context and resources).

"They almost need like a surrogate outside of their brain to do that thing, that, that part of the brain is no longer doing to really initiate the activity. And going back to that idea of inertia, that once you get something moving it's a lot easier to move. And so, encouraging families to be persistent in inviting their loved one out to do things ... " HCP P5

"But since I've mentioned it to my [child], [they have] been trying to, as I say get me out more." PTC P4

"So, my ideal maximum care would have a very nice team ... with people working particularity in mood aspects that are not depression. That is why I was saying maybe a psychologist, or maybe a spiritual councillor. Someone that can talk about different things..." HCP P2

“ ... you see I've been 15 years, I've been diagnosed [with PD] and I just saw a psychiatrist [for the] first time last month." PTC P1

Patients and their caregivers reported apathy causes a change in personhood (Social/professional role and identity, Emotion). However, an important aspect to living with apathy in PD is recognizing that apathy is a part of the disease and not the person (Emotion). Some persons with PD believed apathy was a natural part of aging (So$\mathrm{cial} /$ professional role and identity, Social influences, Beliefs about consequences). Persons with PD and apathy also described the large burden of living with apathy (Emotion). HCP noted the importance of persons with PD and family caregivers adjusting daily activities and expectations as a method of management (Social/professional role and identity, Behavioural regulation).

" ... yeah, things that came naturally before they just don't come naturally now, now its planning like you have to plan. like you really have to think things out ABC whereas before you just sort of did stuff" PTC P1 
"I keep giving books to my children and going here read this pamphlet, you need to understand what she's going through so you have a better understanding why she's looking at you like this and ... She's not being mean or ... It's just not her" PTC P2

"I, while I found it odd I thought well you know maybe this is just part of the aging process ... " PTC P3

" ... whereas the motor symptoms of the disease are frustrating, I find personally this inextricably linked motivation, reward, joy, apathy complex that exist ... the most frustrating part of the disease" PTC P3

" ... we start to talk about other resource that the caregiver may need so that they can care for themselves ... we may start talking with them about the importance, about taking better care of themselves and ... I don't mean letting go but recognizing they need to care for themselves..." HCP P9

\section{Discussion}

In order to understand how to develop an optimal approach to apathy in PD we examined what key stakeholders perceived to be barriers and facilitators to the diagnosis and management of apathy in PD. Framework analysis based on the TDF allows our findings to inform the development of guidelines and interventions [28].

A major theme surrounding diagnostic barriers was the lack of a standardized apathy definition, which limits any possibility for improvement of diagnostic processes. This was clearly expressed by all participants. While validated diagnostic criteria exist and have been suggested for use within the clinical setting, these criteria were not utilized by HCPs in our study population, nor had any persons with PD and apathy been aware or diagnosed with apathy in the clinic $[7,8]$.

Our preceding scoping review came to a similar conclusion; the current lack of a standardized definition of apathy limits our ability to evaluate the effectiveness of available apathy screening tools against gold standard criteria $[19,30]$. While available screening tools have demonstrated diagnostic validity, future research should aim to improve overall quality of evidence by first establishing clear definitions of neuropsychiatric symptoms, such as apathy [30].

Interestingly, a recent study assessing barriers and facilitators to the use of clinical practice guidelines for depression and anxiety in PD or dementia identified similar themes [31]. Overlapping themes included a lack of evidence on depression, anxiety and apathy in PD, lack of awareness and availability of screening tools, and concerns regarding symptomatic overlap [31]. These findings suggest that even where neuropsychiatric symptoms are more understood and where guidelines for HCP exist, the quality and breadth of literature on non-motor symptoms in general, is limited. Future studies should acknowledge and address gaps established by such qualitative research, as these gaps limit the quality of current and future clinical practice guidelines.

A recent study employed the TDF to assess barriers to help seeking for non-motor symptoms in persons with PD [32]. Barriers included patient's lack of knowledge that non-motor symptoms were related to $\mathrm{PD}$, a belief that there were limited treatment options for non-motor symptoms, and a hesitancy to add any pharmacologic interventions to their management plan [32]. These themes closely align with our findings that show patients with PD did not perceive apathy to be a part of PD but rather the natural aging process. Additionally, our findings identified patients and family caregivers have limited treatment options and prefer non-pharmacologic treatments to pharmacologic treatment. Taken together, these studies demonstrate a need for increased awareness that PD is more than a movement disorder. Furthermore, research on non-pharmacological interventions for non-motor symptoms should be given priority, due to it being a preferred method of treatment for end-users.

Interestingly, stakeholders identified the use of qualitative research to better understand apathy in PD as an important area for future research. Currently, there is only one other study that employs qualitative methods, with ours being the second within the literature [20]. This research identified methods for managing apathy in PD should revolve around behavioural interventions and the support of social circles [20]. Both qualitative studies identified that, while HCP may be hesitant to make patients and family caregivers aware of apathy without possibility of treatment, communication regarding the meaning and behavioural implications of this symptom are necessary [20].

Future research may also utilize qualitative methods to better understand how persons with PD and their caregivers conceptualize apathy. This may help inform a universally accepted definition of apathy. Furthermore, future qualitative research studies should be conducted specifically discussing key barriers identified within this research, most importantly the lack treatment methods. Given our findings, that persons with PD and their caregivers prefer non-pharmacological treatment, qualitative research may inform the development of more targeted and preferred treatment options.

Limitations of our study include the small sample size of patients and caregivers. This may in part be explained by our strict inclusion criteria, to ensure only those with pure apathy were included. While the sample size was small, saturation occurred such that no new codes were 
generated following our final focus groups/interviews, in each stakeholder group. This may also in part be explained by the specificity of the topic of investigation [21]. Additionally, we combined interview data with focus group data, to ensure all eligible participants were included regardless of scheduling conflicts. We noted data collected in both interviews and focus groups was similar. Specifically, similar experiences were described concerning overall lack of an official diagnosis of apathy given to persons with PD, the importance of awareness, and the lack of available treatment options, reported by all participants. Our patient sample was relatively young, with a mean age of 66 and primarily included females. Therefore, our population may not be representative of older persons with PD or the primarily male population effected by PD [33]. Furthermore; we excluded individuals with depression and mild cognitive impairment. Often, these symptoms occur with apathy, and thus may limit generalizability of our research. Additionally, as participants were required to contact our study if they were interested in participating, we may have missed recruiting the most apathetic persons with PD due to the inherent nature of this symptom.

\section{Conclusions}

These findings suggest that the process of diagnosing apathy may be improved with increased awareness of the symptoms. Managing apathy in PD requires interdisciplinary teams, which also include family caregivers. We identified that where HCPs perceive lack of knowledge as a barrier to making a diagnosis, persons with PD and family caregivers find just being given a diagnosis facilitates overall understanding. Barriers reported suggest future research must aim to identify a standard definition for apathy, along with validated screening tools and specific treatments, with priority given to non-pharmacologic treatment options.

\section{Abbreviations \\ BCW: Behaviour Change Wheel; CHREB: Conjoint Health Research Ethics Board; COM-B: Capability, Opportunity, Motivation, Behaviour; HCP: Health Care Practitioner; MDC: Movement Disorder Clinic; PD: Parkinson's disease; PTC: Patient and caregiver; SAS: Starkstein Apathy Scale; TDF: Theoretical Domains Framework}

\section{Acknowledgements}

The authors would like to thank Monika Khoury-Dool for her assistance with transcriptions and the Calgary Movement Disorders Clinic for their assistance in this research.

\section{Funding}

This study did not receive any funding.

\section{Availability of data and materials}

The datasets used and/or analyzed during the current study are available from the corresponding author on reasonable request.

\section{Authors' contributions}

BM was responsible for study design, acquisition of data, data analysis, interpretation, and drafting of the manuscript. ZG was involved in study design, acquisition of data, data analysis, and editing of manuscript. $\mathrm{HH}$ was involved in study design, acquisition of data, data analysis, and editing of manuscript. JHL was involved in study design, acquisition of data, data analysis, and editing of manuscript and study supervision. All authors have read and approved the final version of the manuscript.

\section{Ethics approval and consent to participate}

Ethics approval was granted through the Conjoint Health Research Ethics Board (CHREB-17-0669). All researchers involved and participants signed confidentiality agreements and informed consent.

\section{Consent for publication}

Not applicable

\section{Competing interests}

The authors declare that they have no competing interests.

\section{Publisher's Note}

Springer Nature remains neutral with regard to jurisdictional claims in published maps and institutional affiliations.

\section{Author details}

${ }^{1}$ Department of Community Health Sciences, University of Calgary, Foothills Medical Centre, South Tower, Room 1104, 1403-29 St. NW, Calgary, AB T2N 2T9, Canada. ${ }^{2}$ Department of Medicine, University of Calgary, Calgary, Alberta Canada. ${ }^{3}$ Alberta Health Services, Calgary, Alberta, Canada. ${ }^{4}$ Seniors Health Strategic Clinical Network, Alberta Health Services, Calgary, Alberta, Canada. ${ }^{5}$ Departments of Medicine and Community Health Sciences, University of Calgary, Hotchkiss Brain Institute, O'Brien Institute for Public Health,

University of Calgary, Calgary, Alberta, Canada.

Received: 16 October 2018 Accepted: 8 May 2019

Published online: 24 May 2019

\section{References}

1. Pagonabarraga J, Kulisevsky J, Strafella AP, Krack P. Apathy in Parkinson's disease: clinical features, neural substrates, diagnosis, and treatment. Lancet Neurol. 2015;14(5):518-31.

2. den Brok MGHE, van Dalen JW, van Gool WA, Moll van Charante EP, de Bie RMA, Richard E. Apathy in Parkinson's disease: a systematic review and meta-analysis. Mov Disord. 2015;30(6):759-69.

3. Dujardin K, Sockeel P, Devos D, Delliaux M, Krystkowiak P, Destée A, et al. Characteristics of apathy in Parkinson's disease. Mov Disord. 2007:22(6):778-84

4. Marin RS. Apathy: a neuropsychiatric syndrome. J Neuropsychiatry Clin Neurosci. 1991:3(3):243-54.

5. Forjaz MJ, Chandiramani C, Martinez-Martin P. The Burden of Non-Motor Symptoms. In: Handbook of Non-Motor Symptoms in Parkinson's Disease [Internet]. Springer Healthcare UK; 2011 [cited 2017 Feb 16]. p. 13-26. Available from: http://link.springer.com/chapter/10.1007/978-1-908517-60-9_2

6. Benito-León J, Cubo E, Coronell C. On behalf of the ANIMO study group. Impact of apathy on health-related quality of life in recently diagnosed Parkinson's disease: the ANIMO study. Mov Disord. 2012;27(2):211-8.

7. Drijgers RL, Dujardin K, Reijnders JSAM, Defebvre L, Leentjens AFG. Validation of diagnostic criteria for apathy in Parkinson's disease. Parkinsonism Relat Disord. 2010;16(10):656-60.

8. Mulin E, Leone E, Dujardin K, Delliaux M, Leentjens A, Nobili F, et al. Diagnostic criteria for apathy in clinical practice. Int J Geriatr Psychiatry. 2011:26(2):158-65.

9. Robert P, Lanctôt KL, Agüera-Ortiz L, Aalten P, Bremond F, Defrancesco M, et al. Is it time to revise the diagnostic criteria for apathy in brain disorders? The 2018 international consensus group. European Psychiatry. 2018:54:71-6.

10. Leiknes I, Tysnes O-B, Aarsland D, Larsen JP. Caregiver distress associated with neuropsychiatric problems in patients with early Parkinson's disease: the Norwegian ParkWest study. Acta Neurol Scand. 2010;122(6):418-24.

11. Findley $L$. The economic impact of Parkinson's disease. Parkinsonism Relat Disord. 2007;13(Supplement):S8-12. 
12. von Campenhausen S, Winter Y, Rodrigues e Silva A, Sampaio C, Ruzicka E, Barone P, et al. Costs of illness and care in Parkinson's disease: an evaluation in six countries. Eur Neuropsychopharmacol. 2011;21(2):180-91.

13. Leentjens AFG, Dujardin K, Marsh L, Martinez-Martin P, Richard IH, Starkstein $S E$, et al. Anxiety rating scales in Parkinson's disease: critique and recommendations. Mov Disord. 2008;23(14):2015-25.

14. Martinez-Martin P, Leentjens AFG, de Pedro-Cuesta J, Chaudhuri KR, Schrag $A E$, Weintraub $D$. Accuracy of screening instruments for detection of neuropsychiatric syndromes in Parkinson's disease. Mov Disord. 2016;31(3): 270-9.

15. Mohammad D, Ellis C, Rau A, Ruthirakuhan M, Lanctôt KL, Herrmann N. Psychometric properties of apathy scales in Parkinson's disease: a systematic review. Neurodegener Dis Manag. 2018;8(4):267-82.

16. Robert P, Onyike CU, Leentjens AFG, Dujardin K, Aalten P, Starkstein S, et al. Proposed diagnostic criteria for apathy in Alzheimer's disease and other neuropsychiatric disorders. European Psychiatry. 2009;24(2):98-104.

17. Gallagher DA, Schrag A. Psychosis, apathy, depression and anxiety in Parkinson's disease. Neurobiol Dis. 2012;46(3):581-9.

18. Drijgers RL, Aalten P, Winogrodzka A, Verhey FRJ, Leentjens AFG. Pharmacological treatment of apathy in neurodegenerative diseases: a systematic review. Dement Geriatr Cogn Disord. 2009;28(1):13-22.

19. Mele B, Holroyd-Leduc J, Ismail Z, Pringsheim T, Goodarzi Z. Diagnosis, treatment, and Management of Apathy in Parkinson's disease: a scoping review. Manuscript in preparation. 2018;

20. Simpson J, McMillan H, Leroi I, Murray CD. Experiences of apathy in people with Parkinson's disease: a qualitative exploration. Disabil Rehabil. 2015;37(7): $611-9$.

21. Green J, Thorogood N, editors. Qualitative methods for Health Research. 2nd ed. Los Angeles: Sage Publications; 2009. p. 304.

22. Starkstein SE, Mayberg HS, Preziosi TJ, Andrezejewski P, Leiguarda R, Robinson RG. Reliability, validity, and clinical correlates of apathy in Parkinson's disease. J Neuropsychiatry Clin Neurosci. 1992;4(2):134-9.

23. Pedersen KF, Alves G, Larsen JP, Tysnes O-B, Møller SG, Brønnick K Psychometric properties of the Starkstein apathy scale in patients with early untreated Parkinson disease. Am J Geriatr Psychiatry. 2012;20(2):142-8.

24. Buelow MT, Blaine AL. The assessment of risky decision making: a factor analysis of performance on the lowa gambling task, balloon analogue risk task, and Columbia card task. Psychol Assess. 2015;27(3):777-85.

25. Kadhim S, Pringsheim T, Le A, Fiest KM, Patten SB, Prisnie JC, et al. Validating screening tools for depression in Parkinson's disease. Mov Disord. 2018;33(7):1184-6.

26. Castanho TC, Amorim L, Zihl J, Palha JA, Sousa N, Santos NC. Telephonebased screening tools for mild cognitive impairment and dementia in aging studies: a review of validated instruments. Front Aging Neurosci. 2014;6:16

27. Tufford L, Newman P. Bracketing in qualitative research. Qual Soc Work. 2012;11(1):80-96

28. Cane J, O'Connor D, Michie S. Validation of the theoretical domains framework for use in behaviour change and implementation research. Implement Sci. 2012;7:37.

29. Michie S, van Stralen MM, West R. The behaviour change wheel: a new method for characterising and designing behaviour change interventions. Implement Sci. 2011;6:42.

30. Leentjens AFG, Dujardin K, Marsh L, Martinez-Martin P, Richard IH, Starkstein $\mathrm{SE}$, et al. Apathy and anhedonia rating scales in Parkinson's disease: critique and recommendations. Mov Disord. 2008;23(14):2004-14.

31. Goodarzi Z, Hanson H, Jette N, Patten S, Pringsheim T, Holroyd-Leduc J. Barriers and facilitators to the use of guidelines for depression and anxiety in Parkinson's disease or dementia; 2016.

32. Hurt CS, Rixon L, Chaudhuri KR, Moss-Morris R, Samuel M, Brown RG. Identifying barriers to help-seeking for non-motor symptoms in people with Parkinson's disease. J Health Psychol. 2016, 1:1359105316683239.

33. Gillies GE, Pienaar IS, Vohra S, Qamhawi Z. Sex differences in Parkinson's disease. Front Neuroendocrinol. 2014 Aug;35(3):370-84

\section{Ready to submit your research? Choose BMC and benefit from:}

- fast, convenient online submission

- thorough peer review by experienced researchers in your field

- rapid publication on acceptance

- support for research data, including large and complex data types

- gold Open Access which fosters wider collaboration and increased citations

- maximum visibility for your research: over $100 \mathrm{M}$ website views per year

At $\mathrm{BMC}$, research is always in progress.

Learn more biomedcentral.com/submissions 